Immigrant workers play a significant role in the U.S. construction industry. This report summarises our recent findings about disparities in demographics, employment characteristics, health and healthcare, and disproportionate risk of workrelated injuries among these vulnerable workers. The statistics are obtained from several large national datasets in the U.S., including the Current Population Survey, American Community Survey, National Health Interview Survey, Medical Expenditure Panel Survey, the Census of Fatal Occupational Injuries, and the Survey of Occupational Injuries and Illnesses. Data from the Mexican Migration Project, an ongoing study of Mexican migration to the U.S., are also included. SAS 9.4 is employed for the data analysis.

The foreign-born population in the U.S. grew rapidly through mid-2000s, but slowed down since the Great Recession. Only $5 \%$ of current foreign-born construction workers arrived during the period of 2011 and 2013, whereas 10\% entered between 2005 and 2007. In 2015, about 2.4 million construction workers, or nearly a quarter of the industry workforce, were foreign-born; of which $84 \%$ were born in Latin American countries. It is estimated that nearly $75 \%$ of workers migrating from Mexico to the U.S. were undocumented or had false documentation on their first trip.

In general, immigrant construction workers are younger, less educated, and disproportionately work in high-risk occupations. These workers also lag behind other workers in income, health insurance coverage, and health services.

Work-related death rates for immigrant construction workers are consistently higher than other workers. However, this trend is not found in nonfatal injuries. Underreporting in nonfatal injuries is suggested. There are sizable disparities between immigrant construction workers and their native-born counterparts in the U.S. Given the rapid changes in the economy and the dangers associated with construction work, enhanced safety and health surveillance and intervention for immigrant construction workers is urgently needed.

\section{3b TB IN THE WORKPLACE AND BEYOND: CONTRIBUTION OF OCCUPATIONAL HEALTH SERVICES TO TB ELIMINATION IN THE ERA OF MOBILE WORKFORCE}

JJ Bernatas.

\subsection{6/oemed-2018-ICOHabstracts.587}

The challenges posed by TB have changed, especially with the threat of drug-resistant TB. Also, the growing mobility of people including workers is a main factor for disseminating TB faster and farther, thus rending its control even more difficult. While the main objective of occupational health services is to control the risk of TB contamination on the workplace, it should be also to reach out the local communities and thus leveraging the impact of the DOTS activities outside the workplace.

In high TB prevalence countries (HTBPC), TB is a hazard on the workplace, and should be integrated in HIRAC procedures, for having in place the necessary control measures. Cross-sectoral approach involving Ministries of Health and Labour contributes to achieve this objective, following the collaboration that ILO and WHO have already implemented. In
HTBPC, there is an urgent need to put in place measures on the workplace to scale up early diagnosis, adequate treatment, and better individual risk assessment based on personal history of mobility. Better coordination at intra-national, regional, and global levels is required to properly managed mobile workers infected with $\mathrm{TB}$, whether it is latent $\mathrm{TB}$ infection or active TB. Occupational Health Services have an important role to play to move this forward.

In low prevalence TB countries, there is an operational program towards TB elimination, where occupational health services have a role to play. In addition to social determinants, mobility plays an important role in these countries, and the wider availability of tests combined with powerful data management and utilisation of e-Health allows to fast track an outbreak and take the adequate control measures. Illegal foreign workers - usually migrants from HTBC - suffer lack of access to TB diagnosis and treatment, and may expose their families, local communities and coworkers in the workplace.

\section{C EMERGING INFECTIONS AND THE HEALTH RISKS OF MIGRANT WORKERS}

Marlou D Renales.

\subsection{6/oemed-2018-ICOHabstracts. 588}

Global movement of individuals, populations, and products is one of the major factors associated with the emergence and re-emergence of infectious diseases as the pace of global travel and commerce increases rapidly. Travel can be associated with disease emergence because (1) the disease arises in an area of heavy tourism, (2) tourists may be at heightened risk because of their activities, or (3) because they can act as vectors to transport the agent to new areas. Tourists may not stay in the country of destination for a significant period of time, however, workers spend considerable duration of stay due to overseas job contracts.

Migration across health and disease disparities influences the epidemiology of certain diseases globally and in nations receiving migrants. While specific disease-based outcomes may vary between migrant group and location, general epidemiological principles may be applied to any situation where numbers of individuals move between differences in disease prevalence.

Hence, there is a continued interrelationship between disease, travel and migration due to this global economic development affecting the workers who will be hired in the country of destination. The CDC defines 'emerging infectious diseases' as those infections that are increasing over time or threaten to increase. It also defines emerging infectious diseases as new infections resulting from new unknown pathogens, known infections which are increasing over new geographic areas, and known infections that are re-emerging as a result of both resistance to antimicrobial therapies and the failure of public health measures.

This paper discusses these infections related to travel of migrant workers as well as the health risks that they encounter. Current challenges exist in the prevention of transmission to other geographical areas of travel. 